\title{
Identification of Endocrine-Disrupting Compounds Using Nanoelectrospray Ionization Mass Spectrometry
}

\author{
Cédric Bovet ${ }^{a}$, Marc Ruff ${ }^{b}$, Arno Wortmanna ${ }^{a}$, Sylvia Eiler ${ }^{b}$, Florence Granger ${ }^{b}$, Bertran Gerrits ${ }^{c}$, \\ Dino Moras ${ }^{\mathrm{b}}$, and Renato Zenobiª
}

\begin{abstract}
A method using chip-based nanoelectrospray mass spectrometry (nanoESI-MS) is described to detect noncovalent ligand binding to the human estrogen receptor alpha ligand-binding domain ( $\mathrm{hER} \alpha \mathrm{LBD}$ ). This system represents an important environmental interest, because a wide variety of molecules, known as endocrine-disrupting compounds (EDCs), can bind to the estrogen receptor (ER) and induce adverse health effects in wildlife and humans. An efficient analytical method is therefore required to identify EDCs and characterize their solution-phase binding affinity and character (i.e. agonist or antagonist). Using proper experimental conditions, the nanoESI-MS approach allowed the detection of specific ligand interactions with $\mathrm{hER} \alpha \mathrm{LBD}$. The best approach to evaluate solution-binding affinity by nanoESI-MS was to perform competitive binding experiments with 17 $\beta$-estradiol (E2) as a reference ligand. Among the ligands tested, the relative binding affinity for hER $\alpha$ LBD measured by nanoESI-MS was 4-hydroxytamoxifen $\approx$ diethylstilbestrol > E2 >> genistein >> bisphenol A, consistent with the order of the binding affinities in solution. To discern agonist from antagonist, we used the specificity of a coactivator peptide for agonist-bound receptor. A specific coactivator-hER $\alpha$ LBD complex was detected only in the presence of an agonist ligand. Therefore, the specificity of nanoESI-MS combined with its speed (1 min/ligand), low sample consumption ( 90 pmol protein/ligand), and its sensitivity for ligand $(30 \mathrm{ng} / \mathrm{ml})$ demonstrates that this method is promising for the identification and characterization of suspected ER ligands in a high-throughput manner.
\end{abstract}

Keywords: Electrospray ionization mass spectrometry · Endochrine-disrupting compounds · Estrogen receptor · Noncovalent $\cdot$ Solution-binding affinity

${ }^{*}$ Correspondence: Prof. Dr. R. Zenobia

Tel.: +41446324376

Fax: +41446321292

E-mail: zenobi@org.chem.ethz.ch

aDepartment of Chemistry and Applied Biosciences

ETH Zurich

$\mathrm{CH}-8093$ Zurich

bIGBMC (Institut de Génétique et de Biologie Moléculaire et Cellulaire)

Département de Biologie et Génomique Structurales Université Louis Pasteur

U596 INSERM, UMR7104 CNRS

1 rue Laurent Fries

67404 Illkirch; France.

'Functional Genomics Center

UZH I ETH Zurich

$\mathrm{CH}-8057$ Zurich

\section{Introduction}

Within the different objectives of the National Research Programme 50 (NRP 50), the development of suitable analytical strategies to assess the endocrine-disrupting activity of suspected compounds was addressed. Active compounds, known as endocrine-disrupting compounds (EDCs), mimic the action of natural hormones by binding with distinct affinities to the hormone receptors and may induce adverse health effects in humans and wildlife. ${ }^{[1,2]}$ Among the hormone receptors, the estrogen receptor (ER) is a member of the nuclear receptor (NR) superfamily of ligandactivated transcription regulators, which are involved in many processes such as growth, organ differentiation, and development of reproductive tissues. In response to the binding of a ligand to the ligand binding domain (LBD), ER undergoes a conformational change which modulates the recruitment of coactivators required for transcriptional activation of the target genes. ${ }^{[3,4]}$ The ability of ER to bind the coactivator is sensitive to the nature of the bound ligand (i.e. agonist or antagonist). Only agonist binding allows the LBD to further interact with a conserved motif LXXLL (known as NR box, where L is leucine and $\mathrm{X}$ is any amino acid) of coactivators.

The primary questions in the field of EDCs are whether or not a given chemical has an endocrine-disrupting activity, the determination of its solution-phase binding affinity to ER and its agonist/antagonist character. A suitable method should be able to detect intact ligand bound to the ER in a high-throughput manner. For many chemicals, solution-phase binding affinity has been determined by radiolabel assays ${ }^{[5,6]}$ and fluorescence polarization methods. ${ }^{[7-10]}$ The agonist/antagonist character of ligands was mainly revealed with time-resolved fluorescence by measuring the variation of a coactivator peptide affinity against the receptor once incubated with a ligand. ${ }^{[11-14]}$ The synthesis of a specific labelled ligand by these methods is often time consuming and the added marker may alter the ligand-binding interactions with the receptor. In contrast, nondenaturing electrospray ionization mass 
spectrometry (ESI-MS) has successfully demonstrated its capacity for studying noncovalent complexes and for measuring solution-binding constants without any ligand modifications. ${ }^{[15-22]}$ With regard to its speed, sensitivity, and ability to directly monitor intact noncovalent complexes, ESI-MS has the potential to become a superior screening method to investigate the bioactivity of compounds with a suspected endocrine-disrupting activity. The recent development of an automated chip-based nanoflow electrospray (nanoESI) adds other important advantages to ESI-MS for studying protein-ligand complexes, i.e. high sensitivity and low sample consumption combined with high-throughput capability. ${ }^{[23,24]}$

Here, we present an efficient method based on nanoESI-MS for identifying and characterizing compounds with suspected endocrine-disrupting activity. Its development was carried out with a triple mutant $\mathrm{hER} \alpha \mathrm{LBD}$ for which the crystal structure is known. ${ }^{[25]}$ This mutant hER $\alpha$ LBD (below we will use the designation $\mathrm{hER} \alpha \mathrm{LBD}$ for the mutant) has demonstrated to bind estradiol (E2) as strongly as the wild type, which allows us to use it as a model. The gas-phase stability of hER $\alpha$ LBD complexed with a natural hormone, drug molecules, an environmental contaminant, and a phytoestrogen will be investigated with nanoESI-MS. Using competitive binding experiments with a reference ligand, we will further demonstrate the ability of nanoESI-MS to probe the relative solution-binding affinity of different ligands. In addition, we used nanoESI-MS to directly monitor the ligand-dependent recruitment of a coactivator peptide by the $\mathrm{hER} \alpha \mathrm{LBD}$. Because only an agonist ligand promotes the recruitment of the peptide by the receptor, the mass spectrometric detection of an intact noncovalently bound peptide to the receptor will indicate an agonist character for the tested ligand.

\section{Experimental}

\section{Sample Preparation}

The triple mutant hER $\alpha$ LBD was overexpressed in E. coli and purified as previously described. ${ }^{[25]}$ Amino acids sequence 302-553 of $\mathrm{hER} \alpha$ corresponding to the LBD (containing three cysteines to serines mutations at positions 381,417 and 530) was generated in fusion with thioredoxin, six histidine residues, and a thrombin cleavage sequence (MW $43947 \mathrm{Da}$ ). Prior to ESI-MS measurements, the protein stock solution $(4.5 \mathrm{mg} / \mathrm{ml}$ in $10 \%$ [v/v] glycerol, $50 \mathrm{mM} \mathrm{NaCl}$ and $100 \mathrm{mM}$ Tris/HCl, $\mathrm{pH} 8$ ) was desalted and buffer exchanged against $50 \mathrm{mM} \mathrm{NH} 4 \mathrm{OAc}$ (pH 6) using Micro Biospin 6 columns (Bio-rad Laboratories). Fifty microliters of the protein at $30 \mu \mathrm{M}$ diluted in $50 \mathrm{mM} \mathrm{NH} \mathrm{NHAc}_{4} \mathrm{OH} \mathrm{6)}$ were used. As the recovery of the purification step is unknown, the hER $\alpha$ LBD concentration indicated throughout this study is based on a $100 \%$ recovery, an approximation that likely overestimates the protein concentration used during the experiments.

Stock solutions of the different ligands were prepared in ethanol. 17 $\beta$-estradiol (E2), 4-hydroxytamoxifen (OHT) and diethylstilbestrol (DES) were obtained from Sigma, bisphenol A (BA) from Aldrich and genistein (GE) from Fluka. The final ethanol volume of the ligand solution was kept constant at $2 \%$ of the total volume. A steroid receptor coactivator peptide (CAP) was purchased from Anaspec (San Jose, USA) and had the amino acid sequence LTERHKILHRLLQE (MW 1786.1 Da), which contains the typical binding motif LXXLL. The CAP was derived from the sequence of SRC-1 coactivator protein, a member of the p160 class of nuclear hormone receptor coactivators, and contained the second NR box of SRC-1, which has the highest affinity for ER $\alpha .{ }^{[11]}$ Lyophilised CAP was dissolved in water to a final concentration of $100 \mu \mathrm{M}$.

\section{Electrospray Ionization Mass Spectrometry}

ESI mass spectra were acquired on a quadrupole time-of-flight mass spectrometer (Q-ToF ULTIMA, Waters) equipped with an automated chip-based nanoESI system (Nanomate 100, Advion Biosciences). Calibration was performed by using the multiply charged ions produced by a mixture of $1 \mu \mathrm{M}$ myoglobin and trypsinogen dissolved in $\mathrm{MeOH}: \mathrm{H}_{2} \mathrm{O}(1: 1, \mathrm{v} / \mathrm{v})$ with $1 \%(\mathrm{v} / \mathrm{v})$ acetic acid.

The source block was heated to only $40{ }^{\circ} \mathrm{C}$ to prevent dissociation of the noncovalent complexes. The mass spectrometer was tuned with gentle desolvation parameters to maintain hER $\alpha$ LBD-ligand noncovalent complexes intact during their transfer from the solution phase to the mass spectrometer vacuum. The cone and first ion tunnel (RF1) voltages, the parameters which control the kinetic energy of the ions in the source region of the Q-ToF ULTIMA mass spectrometer, were optimized at $80 \mathrm{~V}$ and 60 $\mathrm{V}$, respectively. The pressure in the source region was increased to 4.5 mbar with a Speedivalve (BOC Edwards) to enhance the transmission of high $m / z$ ions ${ }^{[26-28]}$ and to preserve the noncovalent complexes in the gas phase. ${ }^{[15,29-31]}$ After passing the cone and the ion tunnels, the ion beam entered the quadrupole, which was used in RF-only mode, and then passed through a hexapole collision cell pressurized with argon (purity 5.0, PanGas). Collision-induced dissociation (CID) experiments were performed by varying the acceleration voltage (CE), which determines the kinetic energy of the ions when they collide with the collision cell gas. For competitive binding assays and titration ex- periments, the CE voltage was optimized at $10 \mathrm{~V}$. Ions were detected with a multichannel plate (MCP) detector assembly operated at $2250 \mathrm{~V}$.

\section{Data Processing}

Before data processing, each spectrum was background subtracted (fifth order polynomial, 25\% below curve) and smoothed (Savitzky-Gollay smooth, $10 \times 5$ channels) with the MassLynx software (version 4.0). For CID experiments, the CE voltage giving a $50 \%$ complex dissociation was calculated by fitting the dissociation curve with a sigmoidal curve. The relative abundances of the free and the ligand-bound protein cannot be directly obtained from the relative peak intensities, because the peak position of the ligand-bound protein partially matches the one of the free protein. It was thus assumed that the peak of the ligand-bound protein differs only in its position on the mass scale and its amplitude, but not in its shape. To calculate the bound-to-free protein ratio $\mathrm{R}$, a reference nanoESI mass spectra of hER $\alpha$ LBD alone was measured under the same MS conditions as hER $\alpha$ LBD incubated with a ligand. The corresponding ion peak was duplicated and shifted by the respective $\mathrm{m} / \mathrm{z}$ of the ligand. The abundances of the free and bound protein were then evaluated by adjusting the peak heights of the reference mass spectra with the mass spectra of $h E R \alpha$ LBD incubated with the ligand.

\section{Results and Discussion}

\section{Detection of hER $\alpha$ LBD-Ligand \\ Complexes by NanoESI-MS}

The ability to detect noncovalent complexes using ESI-MS depends on both instrumental and solution conditions. To preserve intact complexes in solution, it is necessary to use an aqueous environment, which requires harsher MS transfer/desolvation conditions compared to organic solvents, under which the complex may be destroyed. Therefore, a compromise between sufficient desolvation and intact complex detection has to be found. As a first step, the solution conditions (e.g. $\mathrm{pH}$ and buffer concentration) were optimized to simulate a near-native environment for $\mathrm{hER} \alpha \mathrm{LBD}$ in order to preserve noncovalent interactions, in particular ligand binding. Under denaturing conditions, a broad distribution of charge states $(21+$ to $60+)$ consistent with ions of the unfolded hER $\alpha$ LBD monomer was observed (data not shown). With nondenaturing conditions (Fig. 1), the resulting spectra show three charge state envelopes, which were assigned to the hER $\alpha$ LBD homodimer (labelled $\mathrm{D} n+, \mathrm{m} / \mathrm{z}$ range 4000-5600), the folded monomer (labelled $\mathrm{M} \mathrm{n}+, m / z$ range 2500-4000) and the unfolded monomer ( $\mathrm{m} / \mathrm{z}$ range $900-2500)$. Increasing the $\mathrm{pH}$ from 6 to 7.4 enhanced 
the relative homodimer abundance and decreased the homodimer and monomer average charge state (from +18.4 to +18 and from +13.1 to +12.7 , respectively). This suggests that a higher $\mathrm{pH}$ better simulates a native environment for the protein (native solution $\mathrm{pH}$ of this protein is 7-8). However, the width of the peaks measured at pH 7.4 (Fig. 1b) indicates more trapped water/salt molecules in the folded structure, which may complicate the detection of low molecular weight EDCs (MW 200-300 Da). A slightly acidic $\mathrm{pH}$ was therefore selected for the analysis of $\mathrm{hER} \alpha \mathrm{LBD}-$ ligand complexes to improve the sensitivity and decrease the peak width observed in Fig. 1b. The unfolded $h E R \alpha$ LBD monomer (charge state distribution below $m / z$ 2500) observed under nondenaturing conditions was certainly due to a partial misfolding during the overexpression or protein denaturation due to the freezing/thawing cycles before sample preparation.

The detection of noncovalent $\mathrm{hER} \alpha$ LBD-ligand complexes by ESI-MS depends on the collision frequency of the ions with the residual gas along the path from atmosphere to vacuum and on the center-of-mass energy. Therefore, a careful selection of the MS transfer conditions, i.e. the transfer voltages and the gas pressure, is required to keep the internal energy of the ions below the dissociation threshold of the complex. ${ }^{[33]}$ Experimentally, this is controlled by reducing the transfer voltages, which control the kinetic energy of the ions, and/or increasing the source pressure. ${ }^{[15,29-31]}$ By selecting MS transfer conditions carefully (see Experimental part), intact $\mathrm{hER} \alpha \mathrm{LBD}$ monomer and homodimer bound to one and two E2 molecules, respectively, were detected (Fig. 2 ). Subjecting the ions to harsher MS transfer conditions (i.e. higher transfer voltages) helped to decluster them and produced narrower peaks with higher signal-to-noise ratio, but also led to the dissociation of $h E R \alpha$ LBD bound to E2 (Fig. 2). The heavier homodimer ions require more collisions than the lighter monomer ions for building up sufficient internal energy for dissociation to take place. Therefore, the transfer potential should be selected carefully to find a balance between good ion desolvation and complex dissociation.

Since nonspecific protein-ligand aggregation cannot generally be excluded during the ionization process, ${ }^{[34]}$ the experiments were repeated by incubating hER $\alpha$ LBD with an inactive cholesterol derivative (4-cholesten-3-one). Under the same instrumental conditions, the absence of binding with 4-cholesten-3-one validates the detection of a specific hER $\alpha$ LBD-E2 complex by nanoESI-MS (data presented in [32]). The observed 1:1 monomer:E2 and 1:2 homodimer:E2 stoichiometry of the gasphase complexes further supports the specificity of the receptor-ligand complex (Fig.

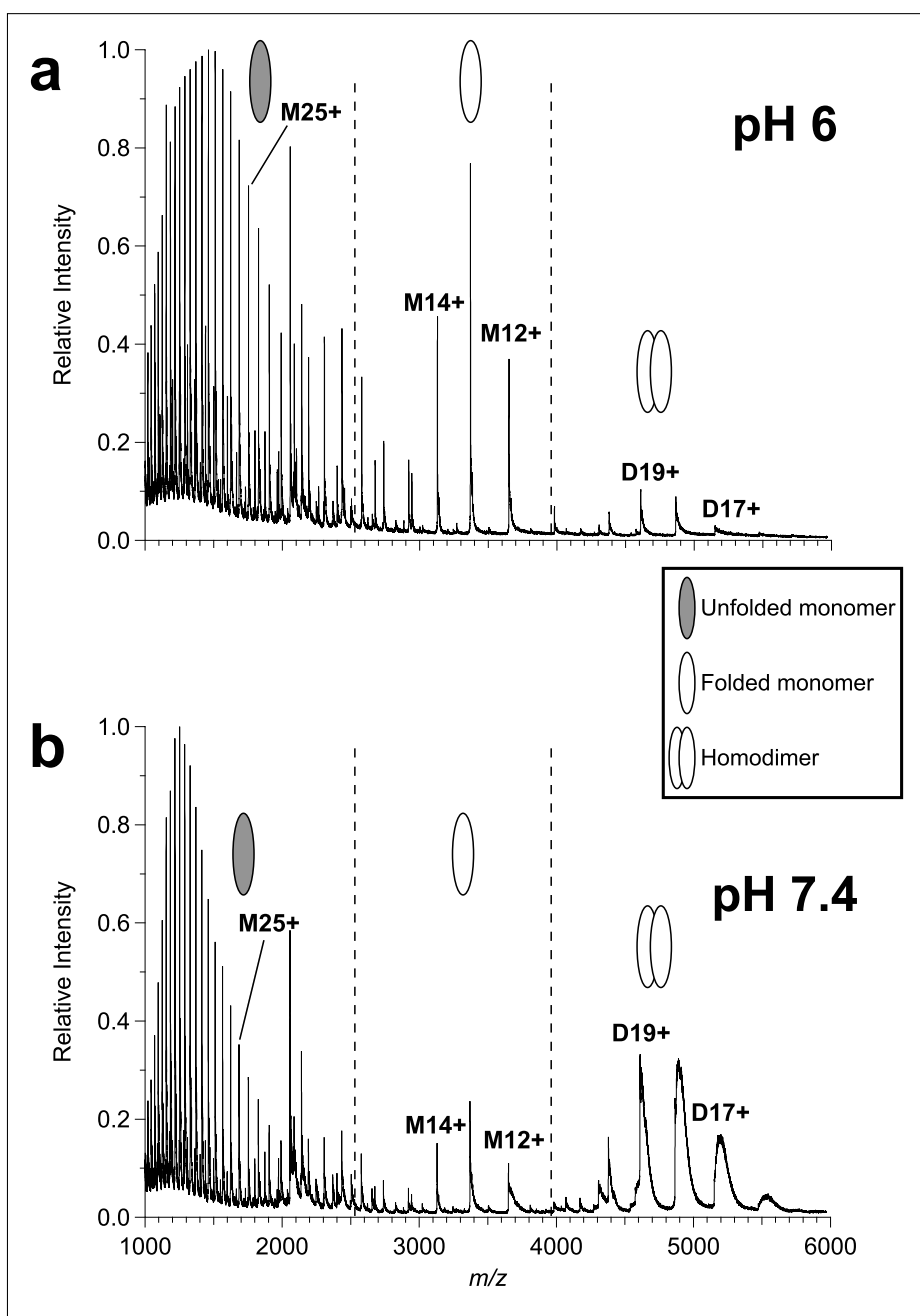

Fig. 1. Positive nanoESI mass spectra of $h E R \alpha$ LBD acquired under different $\mathrm{pH}$ conditions.

(a) $\mathrm{hER} \alpha \mathrm{LBD}$ in 50 $\mathrm{mM} \mathrm{NH}_{4} \mathrm{OAc}, \mathrm{pH} 6$. (b) hER $\alpha$ LBD in $50 \mathrm{mM} \mathrm{NH}_{4} \mathrm{OAc}$, $\mathrm{pH}$ 7.4. The broad homodimer peak under (b) indicates that more water/salt molecules are trapped in the folded structure (adapted from [32]).

2). Control experiments were also needed to exclude protein aggregation during the ESI process and confirm the specificity of the noncovalently bound hER $\alpha$ LBD homodimer. The disappearance of the homodimer envelope under denaturing conditions (data not shown) is consistent with a specific interaction, but is not sufficient to exclude nonspecific aggregation of $\mathrm{hER} \alpha \mathrm{LBD}$ monomer during the ionization process. The nanoESI-MS data obtained after incubation with $\mathrm{E} 2$, i.e. the detection of folded monomer and homodimer bound to one and two E2 molecules, respectively, clearly support the assignment to folded hER $\alpha$ LBD monomer and homodimer.

\section{Solution-phase Binding Affinity Measured by NanoESI-MS}

The above results demonstrate that nanoESI-MS is suitable to detect specific hER $\alpha$ LBD-ligand complexes, which allows compounds with suspected endocrine-disrupting activity to be identified. With the chip-based nanoESI system, an analysis time of $1 \mathrm{~min} /$ ligand could be obtained, resulting in consumption of $<90 \mathrm{pmol}$ of protein (i.e. $5 \mu$ of protein at $0.6 \mathrm{mg} / \mathrm{ml}, \mathrm{MW}=43947 \mathrm{Da}$ ). The limit of detection of a bound ligand is in the range of $30 \mathrm{ng} / \mathrm{ml}$. With the present level of clustering, and given the accuracy of the
Q-ToF instrument, it is possible to detect a mass difference of $0.4 \mathrm{Da}$ for the monomer charge state +12 . Thus, this currently allows resolution of the mass of unknown ligand bound to the hER $\alpha$ LBD with a 5 Da accuracy. To be competitive with conventional analytical methods, nanoESI should be able to measure the wide range of solution binding affinities of EDCs against ER. A number of studies have shown the capability of ESI for providing solution-phase binding affinities by competition experiments and titration experiments. ${ }^{15-22]}$ A complementary approach, collision-induced dissociation (CID), consists of dissociating the noncovalent complex by increasing the collision energy (CE) voltage. The acceleration $\mathrm{CE}$ voltage required to dissociate $50 \%$ of the complex $\left(\mathrm{CE}_{50}\right)$ is a measure of the complex gas-phase stability. To determine the best ESI approach for evaluating the solutionphase binding affinity of EDCs, we investigated CID, the competition experiment and the titration experiment approaches for two pharmaceutical compounds, OHT and DES; an environmental estrogenic compound, BA; and a phytoestrogen, GE. These ligands were selected because they have a wide range of affinities for $\mathrm{hER} \alpha \mathrm{LBD}$ and represent the different classes of interest for EDCs. The MS data were compared with the relative 


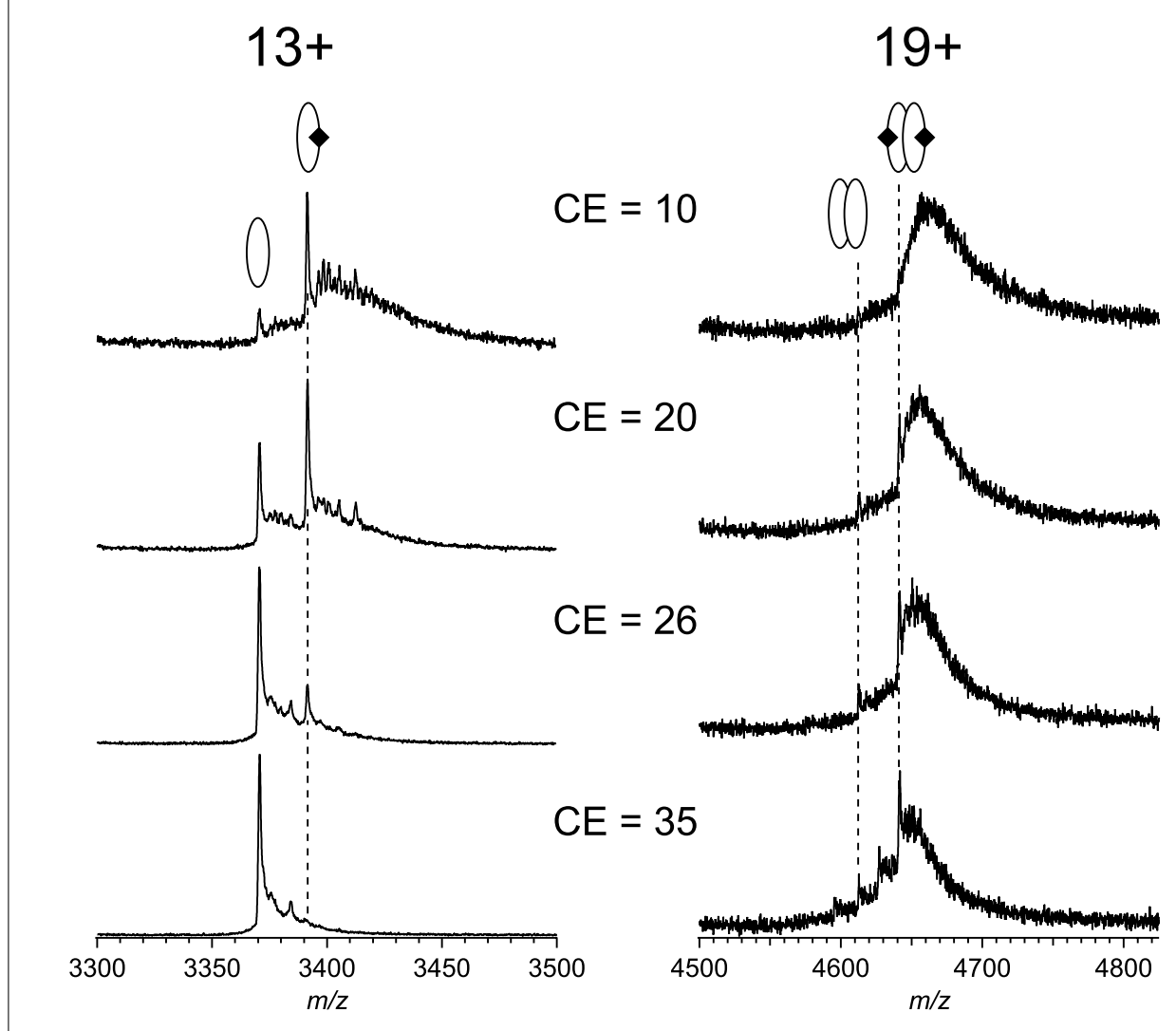

Fig. 2. Gas-phase stability analysis of hER $\alpha$ LBD-E2 complex (in $50 \mathrm{mM} \mathrm{NH}_{4} \mathrm{OAc}, \mathrm{pH}$ 6) at different collision energies (CE). Only the monomer charge state $13+$ and the homodimer charge state 19+ are shown. The complex gradually dissociates when the accelerating CE voltage is increased. This is result of the more energetic ion collisions with the collision cell gas (adapted from [32]).

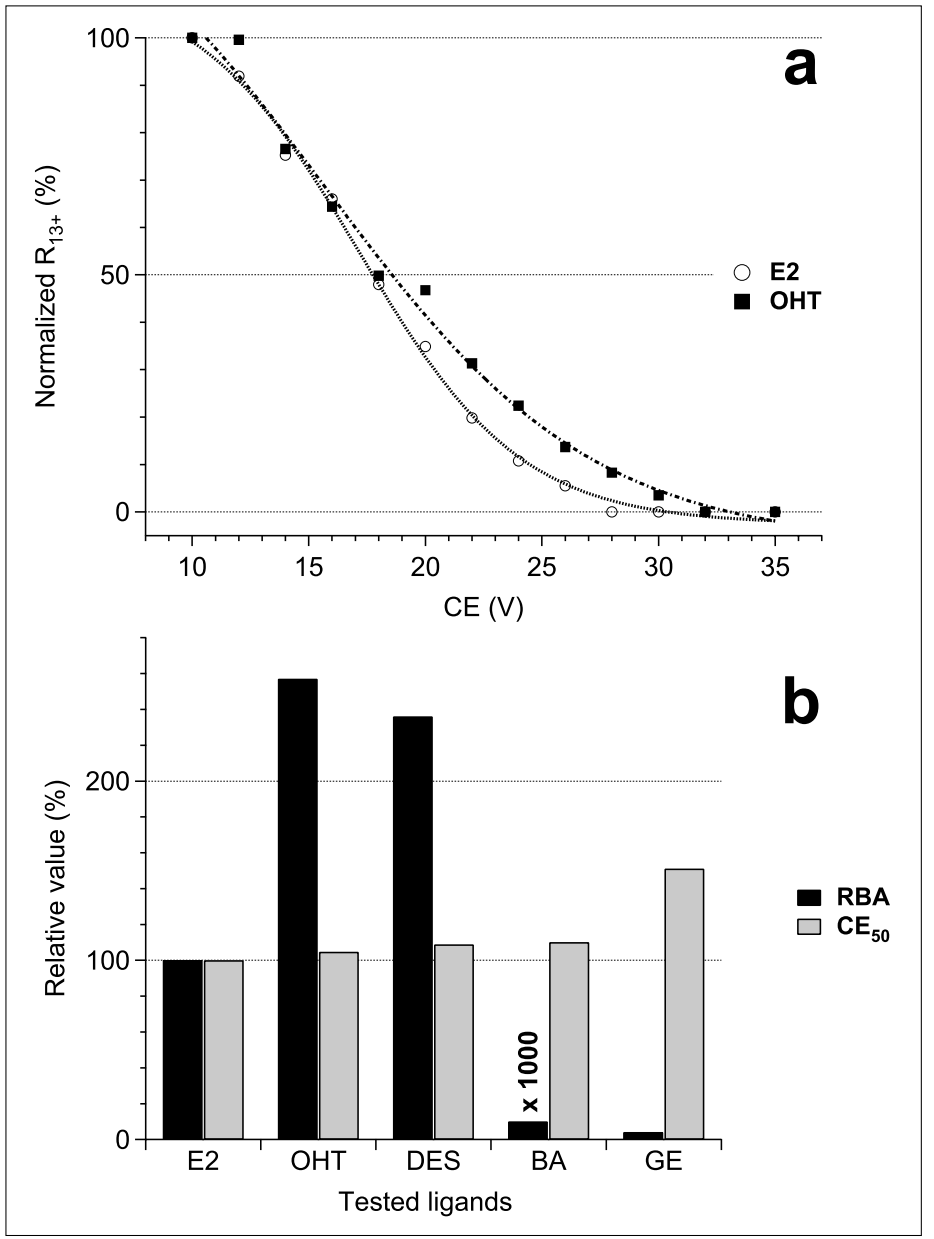

binding affinities (RBAs) determined by competition binding assays of radiolabeled E2 for the hER $\alpha .{ }^{[6]}$

CID analysis was performed on the $13+$ charged complex of hER $\alpha$ LBD monomer ion (Fig. 3a). Every $\mathrm{CE}_{50}$ value was normalized to a reference ligand, $\mathrm{E} 2\left(\mathrm{CE}_{50}(\mathrm{E} 2)=\right.$ $100 \%$ ). As shown in Fig. 3b, the gas-phase stability data clearly indicate that measurements of relative gas-phase stability for $\mathrm{hER} \alpha \mathrm{LBD}-$ ligand complexes do not reflect the binding affinity in solution, in agreement with other ESI studies. ${ }^{[35-38]}$ These results confirm the prominent role of hydrophobic contacts for stabilizing ER-ligand complexes in solution, ${ }^{[39]}$ an interaction that disappears during the removal of solvent molecules in the ESI process. ${ }^{[40]}$

Qualitative analysis was then performed using competitive binding experiments in which hER $\alpha$ LBD was incubated with a reference ligand (E2) and the target ligand. The peak height of the different protein-ligand complexes was taken to be proportional to their relative solution affinity. Due to the small mass of the ligands relative to the protein, a similar ionization efficiency can be assumed for the free and bound protein. ${ }^{[41]}$ When DES or OHT was added with E2 to hER $\alpha$ LBD at an equimolar concentration (i.e. $0.5 \mu \mathrm{M}$ each), only the complex with DES or OHT was observed, while only the E2 complex was detected when incubation was done with BA and GE. Therefore, OHT and DES have a stronger solution affinity for $h E R \alpha$ LBD relative to E2; BA and GE must have a lower affinity. The ability of a high-affinity ligand to displace a low-affinity ligand from the hER $\alpha$ LBD is another demonstration of the specificity of the protein-ligand interactions detected by nanoESI-MS. Subsequent competition experiments were performed between the stronger (OHT and DES) and lower (BA and GE) affinity ligands. The resulting nanoESI mass spectra are presented in Fig. 4 and suggest the following relative solution affinity of hER $\alpha$ LBD-ligand complexes: $\mathrm{OHT} \approx \mathrm{DES}>\mathrm{E} 2>>\mathrm{GE}>>\mathrm{BA}$. This is in agreement with the binding affinity measured in solution (i.e. RBA values presented in Fig. 3b). Thus, nanoESI-MS can qualitatively estimate the solution-binding affinity of EDCs.

Finally, the binding constant of E2 against $\mathrm{hER} \alpha \mathrm{LBD}$ was also evaluated by titration experiments (data presented in [32]). The limited reproducibility of the bound-to-free receptor ratio measured by nanoESI-MS for this system only yielded a rough estimate for the binding constants $\left(\mathrm{K}_{\mathrm{d}}\right)$ in the low nanomolar range for E2 (data presented in [32]), in reasonable agreement with the 0.92 nM reported in the literature. ${ }^{[25]}$ Although a number of studies have demonstrated that binding affinities determined by ESI are in a good agreement with solution-phase data, ${ }^{[15,16,20-22]}$ the use of correction factors 

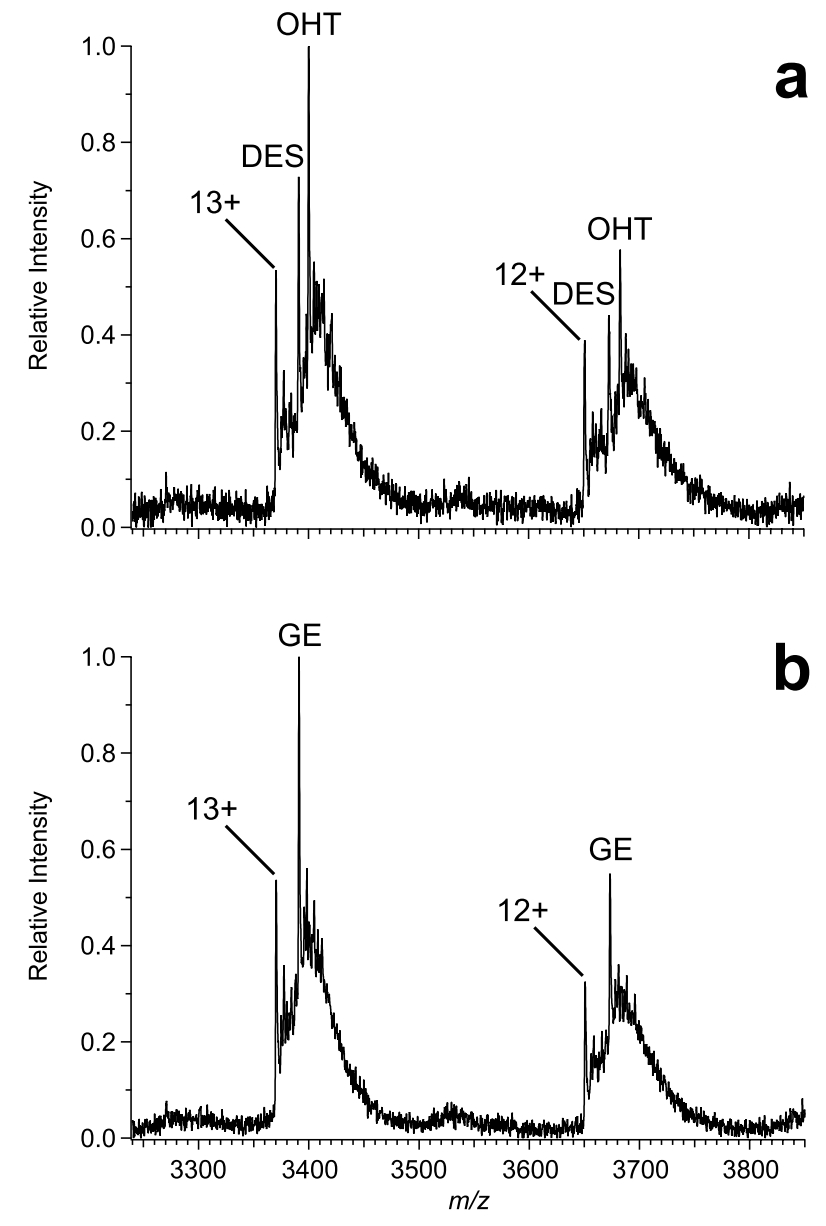

Fig. 4. Competitive binding experiments analysis of $h E R \alpha$ LBD with a mixture of (a) OHT and DES; (b) GE and BA. NanoES mass spectra of $h E R o$ LBD were acquired after incubation with an equimolar mixture of ligand (i.e. 0.5 $\mu \mathrm{M}$ of each) in 50 $\mathrm{mM} \mathrm{NH}_{4} \mathrm{OAc}(\mathrm{pH} 6)$ (adapted from [32]). Abbreviations for the tested ligands are presented in the Experimental section or assumptions to derive relative solution concentrations from the ion intensities of the different species generally limits the application of this approach. ${ }^{[15,18,42]}$ According to our investigations, the preferred method for evaluating solution-binding affinities of EDCs using nanoESI-MS is clearly competitive binding experiments, which yields a relative affinity order.

\section{Discerning Agonist from Antagonist Ligands by NanoESI-MS}

To discern agonist from antagonist ligand, we monitored the ligand-dependent recruitment of a coactivator peptide (CAP, see Experimental section) by the receptor with nanoESI-MS. Because only agonist binding allows the LBD to further interact with CAP, the detection of a specific hER $\alpha$ LBD-CAP complex by nanoESI-MS after incubation with a ligand will indicate an agonist character for the tested compound. CAP contained the conserved motif LXXLL of coactivators, a short sequence necessary and sufficient to mediate the binding of the coactivators to ligand-bound receptor. ${ }^{[14,43]}$

To validate an agonist-dependent interaction of CAP with the hER $\alpha$ LBD, we incubated the receptor with a known agonist and antagonist ligand (i.e. E2 and OHT, respec- tively). Because the homodimer ion distribution $(\mathrm{m} / \mathrm{z} 4000-5600)$ is not sufficiently resolved to discern the ligand-bound from the apo homodimer, our analysis is based on the monomer range $(\mathrm{m} / \mathrm{z}, 2500-4000)$. For simplicity, the analysis is discussed for the monomer charge state 14+. Once incubated with E2, the apo and E2-bound hER $\alpha$ LBD were detected (Fig. 5a). After incubation with E2 and CAP, the apo and ligandbound monomer were detected with a new pair of peaks appearing at higher $\mathrm{m} / \mathrm{z}$ values (Fig. 5b, $\mathrm{m} / \mathrm{z}$ 3250-3350). These new species correspond to the specific hER $\alpha$ LBD-CAP complex with and without ligand. The incubation with the antagonist OHT only led to a very small intensity of the $\mathrm{hER} \alpha \mathrm{LBD}-\mathrm{CAP}$ complex, i.e. there is very little binding of CAP to hER $\alpha$ LBD (Fig. 5c). Therefore, our results support the ability of this short peptide to differentiate ligand-induced conformational changes in the receptor. The nanoESI-MS approach reveals that agonist and antagonist ligands promote different receptor conformational changes, which differentially expose the coactivator-binding surface of the LBD and allow agonist from antagonist ligand to be discerned. Because in vitro coactivator peptide recruitment profiles have previously shown a good correlation with cell-based assays, ${ }^{[44]}$ the nanoESI approach presented here can be used to suggest the biological consequences of ligand binding within a cell. The short analysis time of mass spectrometry is a real advantage compared to conventional transactivation assays, which require time-consuming and complex steps for handling specific cell cultures.

\section{Conclusions and Outlook}

We have shown that nanoESI-MS is an efficient identification and characterization method for suspected EDCs in terms of specificity, sample consumption, speed, and the possibility for automation. Ligand binding was clearly observed, even for lowaffinity ligands. The best approach to evaluate qualitatively solution-binding affinity of ligand to hER $\alpha$ LBD by nanoESI-MS was a competition experiment with a reference ligand. The ligand-dependent binding of a coactivator peptide by the hER $\alpha$ LBD allows agonists from antagonists to be discerned with mass spectrometry. Based on these findings, we propose a simple in vitro methodology using nanoESI-MS to identify and characterize compounds with suspected endocrine-disrupting activity. This method will be extended to a larger library of compounds. In addition to nanoESI-MS, we plan to explore the use of high-mass matrix-assisted laser desorption/ionization mass spectrometry (MALDI-MS) combined with chemical cross-linking to detect intact coactivator-receptor complexes after ligand incubation. Prior to MALDI analysis, cross-linking chemistry can be used to prevent protein complex dissociation induced by standard MALDI protocols, which extend the application of MALDIMS to the area of large noncovalent complexes. ${ }^{[45,46]}$

\section{Acknowledgments}

This work was supported by the Swiss National Science Foundation (projects no. 4050-104373 and 200020-111831) and the SPINE 1 and 2 European Project (FP6 Contract $\mathrm{N}^{\circ}$ QLG2-CT-2002-00988 and 031220). We are grateful to the Functional Genomics Center Zurich and Advion Biosciences for providing technical support, and to Novartis Pharma AG for partial funding.

Received: March 22, 2008

[1] T. Colborn, F. S. V. Saal, A. M. Soto, Environ. Health Perspect. 1993, 101, 378.

[2] P. T. C. Harrison, P. Holmes, C. D. N. Humfrey, Sci. Total Environ. 1997, 205, 97.

[3] N. J. McKenna, R. B.Lanz, B. W. O'Malley, Endocr. Rev. 1999, 20, 321.

[4] D. Robyr, A. P. Wolffe, W. Wahli, Mol. Endocrinol. 2000, 14, 329.

[5] R. M. Blair, H. Fang, W. S. Branham, B. S. Hass, S. L. Dial, C. L. Moland, W. D. Tong, 


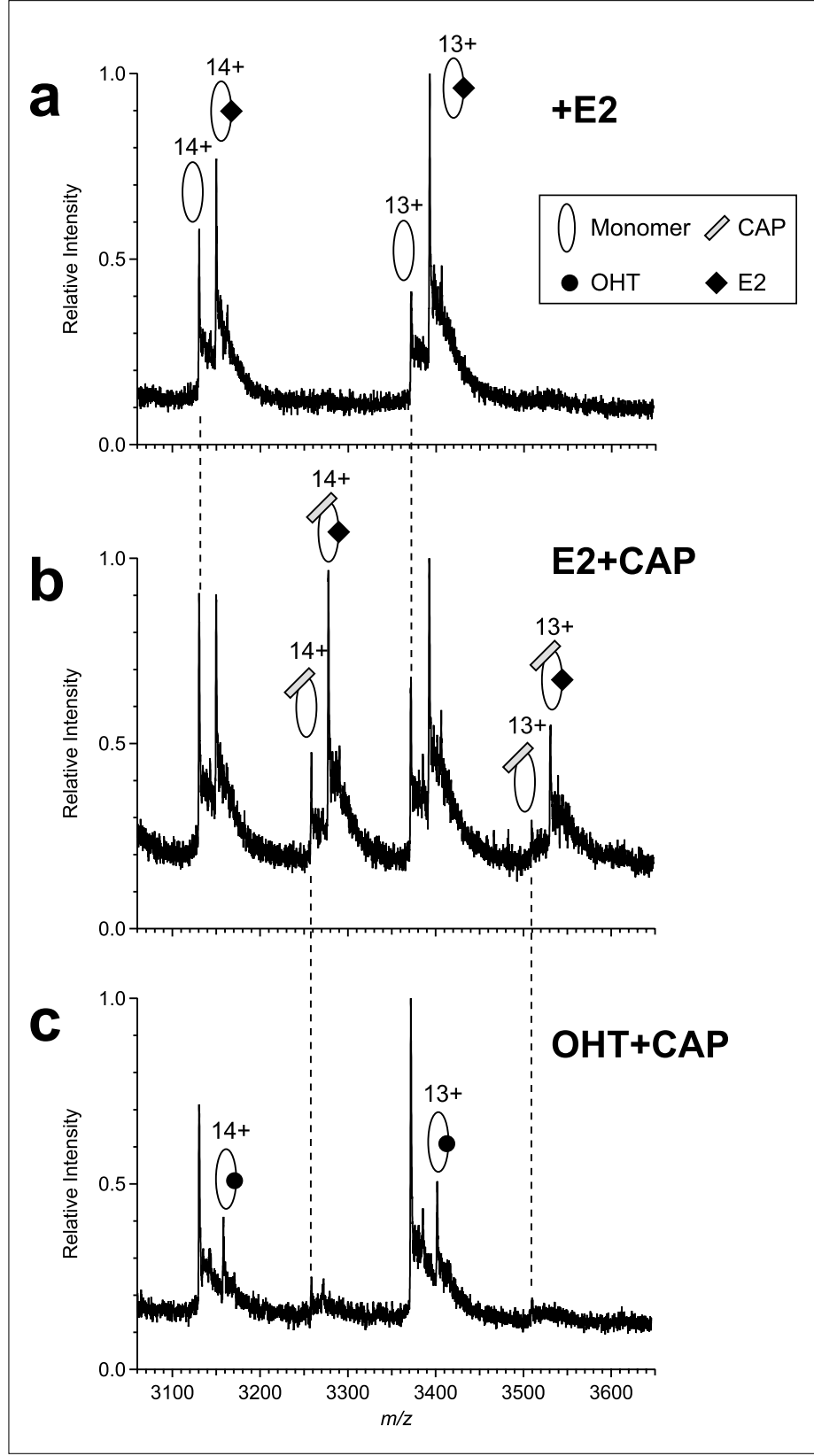

[21] S. Wendt, G. McCombie, J. Daniel, A. Kienhofer, D. Hilvert, R. Zenobi, J. Am. Soc. Mass Spectrom. 2003, 14, 1470.

[22] A. Wortmann, F. Rossi, G. Lelais, R. Zenobi, J. Mass Spectrom. 2005, 40, 777.

[23] S. Zhang, C. K. Van Pelt, D. B. Wilson, Anal. Chem. 2003, 75, 3010.

[24] C. A. Keetch, H. Hernandez, A. Sterling, M. Baumert, M. H. Allen, C. V. Robinson, Anal. Chem. 2003, 75, 4937.

[25] M. Gangloff, M. Ruff, S. Eiler, S. Duclaud, J. M. Wurtz, D. Moras, J. Biol. Chem. 2001, 276, 15059.

[26] F. Sobott, H. Hernandez, M. G. McCammon, M. A. Tito, C. V. Robinson, Anal. Chem. 2002, 74, 1402.

[27] M. a. Tito, J. Miller, N. Walker, K. F. Griffin, E. D. Williamson, D. Despeyroux-Hill, R. W. Titball, C. V. Robinson, Biophys. J. 2001, 81, 3503.

[28] I. V. Chernushevich, B. A. Thomson, Anal. Chem. 2004, 76, 1754.

Fig. 5. NanoESI-MS reveals that an agonist ligand enhances the peptide recruitment by the hER $\alpha$ LBD. Normalized nanoESI mass spectra of hER $\alpha$ LBD representing the monomer charge state $14+$ and $13+$ of (a) $\mathrm{hER} \alpha \mathrm{LBD}$ incubated with the agonist E2; (b) $\mathrm{hER} \alpha \mathrm{LBD}$ incubated with CAP and E2; (c) $\mathrm{hER} \alpha \mathrm{LBD}$ incubated with CAP and the antagonist $\mathrm{OHT}$. $(\diamond)$ and $(\bullet)$ represent the bound E2 and $\mathrm{OHT}$, respectively. Abbreviations for the tested ligands are presented in the Experimental section
L. M. Shi, R. Perkins, D. M. Sheehan, Toxicol. Sci. 2000, 54, 138.

[6] G. G. J. M. Kuiper, J. G. Lemmen, B. Carlsson, J. C. Corton, S. H. Safe, P. T. van der Saag, P. van der Burg, J. A. Gustafsson, Endocrinology 1998, 139, 4252.

[7] R. Bolger, T. E. Wiese, K. Ervin, S. Nestich, W. Checovich, Environ. Health Perspect. 1998, 106, 551.

[8] K. Ohno, T. Fukushima, T. Santa, N. Waizumi, H. Tokuyama, M. Maeda, K Imai, Anal. Chem. 2002, 74, 4391.

[9] K. Ohno, S. Suzuki, T. Fukushima, M. Maeda, T. Santa, K. Imai, Analyst 2003, $128,1091$.

[10] G. N. Nikov, N. E. Hopkins, S. Boue, W. L. Alworth, Environ. Health Perspect. 2000, $108,867$.

[11] K. S. Bramlett, Y. Wu, T. P. Burris, Mol. Endocrinol. 2001, 15, 909.

[12] J. D. Norris, L. A. Paige, D. J. Christensen, C. Y. Chang, M. R. Huacani, D. Fan, P. T. Hamilton, D. M. Fowlkes, D. P. McDonnell, Science 1999, 285, 744.

[13] M. S. Ozers, K. M. Ervin, C. L. Steffen,
J. A. Fronczak, C. S. Lebakken, K. A. Carnahan, R. G. Lowery, T. J. Burke, Mol. Endocrinol. 2005, 19, 25.

[14] L. A. Paige, D. J. Christensen, H. Gron, J. D. Norris, E. B. Gottlin, K. M. Padilla, C. Y. Chang, L. M. Ballas, P. T. Hamilton, D. P. McDonnell, D. M. Fowlkes, Proc. Natl. Acad. Sci. 1999, 96, 3999.

[15] A. Tjernberg, S. Carno, F. Oliv, K. Benkestock, P. O. Edlund, W. J. Griffiths D. Hallen, Anal. Chem. 2004, 76, 4325.

[16] T. J. D. Jorgensen, P. Roepstorff, A. J. R Heck, Anal. Chem. 1998, 70, 4427.

[17] K. A. Sannes-Lowery, R. H. Griffey, S. A Hofstadler, Anal. Biochem. 2000, 280, 264.

[18] V. Gabelica, N. Galic, F. Rosu, C. Houssier, E. De Pauw, J. Mass Spectrom. 2003, 38, 491.

[19] K. De Vriendt, G. Van Driessche, B. Devreese, C. Bebrone, C. Anne, J. M. Frere, M. Galleni, J. Van Beeumen, J. Am. Soc. Mass Spectrom. 2006, 17, 180.

[20] J. M. Daniel, G. McCombie, S. Wendt, R. Zenobi, J. Am. Soc. Mass Spectrom. 2003, 14,442 .
[29] S. Sanglier, H. Ramstrom, J. Haiech, E. Leize, A. Van Dorsselaer, Int. J. Mass Spectrom. 2002, 219, 681.

[30] A. Schmidt, U. Bahr, M. Karas, Anal. Chem. 2001, 73, 6040.

[31] N. Tahallah, M. Pinkse, C. S. Maier, A. J. R. Heck, Rapid Commun. Mass Spectrom. 2001, 15, 596.

[32] C. Bovet, A. Wortmann, S. Eiler, F. Granger, M. Ruff, B. Gerrits, D. Moras, R. Zenobi, Protein Sci. 2007, 16, 938.

[33] F. Sobott, M. G. McCammon, H. Hernandez, C. V. Robinson, Philos. Trans. R. Soc. London, Ser. A 2005, 363, 379.

[34] J. A. Loo, Mass Spectrom. Rev. 1997, 16 , 1.

[35] V. J. Nesatyy, J. Mass Spectrom. 2001, 36, 950.

[36] S. Pan, X. J. Sun, J. K. Lee, Int. J. Mass Spectrom. 2006, 253, 238.

[37] A. van der Kerk-van Hoof, A. J. R. Heck, $J$. Mass Spectrom. 1999, 34, 813.

[38] Q. Y. Wu, J. M. Gao, D. JosephMcCarthy, G. B. Sigal, J. E. Bruce, G. M. Whitesides, R. D. Smith, J. Am. Chem. Soc. 1997, 119, 1157.

[39] A. K. Shiau, D. Barstad, P. M. Loria, L. Cheng, P. J. Kushner, D. A. Agard, G. L. Greene, Cell 1998, 95, 927.

[40] C. V. Robinson, E. W. Chung, B. B. Kragelund, J. Knudsen, R. T. Aplin, F. M. Poulsen, C. M. Dobson, J. Am. Chem. Soc. 1996, 118,8646

[41] M. Peschke, U. H. Verkerk, P. Kebarle, $J$. Am. Soc. Mass Spectrom. 2004, 15, 1424.

[42] D. A. Annis, G. W. Shipps, Jr., Y. Deng, J. Popovici-Muller, M. A. Siddiqui, P. J. Curran, M. Gowen, W. T. Windsor, Anal. Chem. 2007, 79, 4538.

[43] D. M. Heery, E. Kalkhoven, S. Hoare, M. G. Parker, Nature 1997, 387, 733.

[44] M. A. Iannone, C. A. Simmons, S. H. Kadwell, D. L. Svoboda, D. E. Vanderwall, S. J. Deng, T. G. Consler, J. Shearin, J. G. Gray, K. H. Pearce, Mol. Endocrinol. 2004, 18,1064

[45] A. Nazabal, R. J. Wenzel, R. Zenobi, Anal. Chem. 2006, 78, 3562.

[46] O. Yanes, A. Nazabal, R. Wenzel, R. Zenobi, F. X. Aviles, J. Proteome Res. 2006, 5, 2711 